\title{
Silyl Radical-Mediated Activation of Sulfamoyl Chlorides Enables Direct Access to Aliphatic Sulfonamides from Alkenes
}

\author{
Sandrine M. Hell, ${ }^{\dagger}$ Claudio F. Meyer ${ }^{\dagger,}{ }^{\star}$ Gabriele Laudadio,${ }^{\S}$ Antonio Misale,${ }^{\ddagger}$ Michael C. Willis, ${ }^{\dagger}$ Tim- \\ othy Noël, ${ }^{\S}$ Andrés A. Trabanco, ${ }^{\ddagger}$ and Véronique Gouverneur* ${ }^{*}$ \\ $\dagger$ University of Oxford, Chemistry Research Laboratory, 12 Mansfield Road, Oxford, OX1 3TA (United-Kingdom) \\ * Discovery Chemistry, Janssen Research and Development, Jarama 75A, Toledo, E-45007 (Spain) \\ $\S$ Micro Flow Chemistry and Synthetic Methodology, Department of Chemical Engineering and Chemistry, Eindhoven Uni- \\ versity of Technology, Het Kranenveld, Bldg 14 - Helix, 5600 MB Eindhoven (The Netherlands)
}

\section{Supporting Information Placeholder}

\begin{abstract}
Single electron reduction is more challenging for sulfamoyl chlorides than sulfonyl chlorides. However, sulfamoyl and sulfonyl chlorides can be easily activated by $\mathrm{Cl}$-atom abstraction by a silyl radical with similar rates. This later mode of activation was therefore selected to access aliphatic sulfonamides applying a single-step hydrosulfamoylation using inexpensive olefins, tris(trimethylsilyl)silane and photocatalyst Eosin Y. This late-stage functionalization protocol generates molecules as complex as sulfonamide-containing cyclobutyl-spirooxindoles for direct use in medicinal chemistry.
\end{abstract}

Since the discovery of the antibacterial drug Prontosil in the late 30 's, the application of sulfonamides in medicinal chemistry has been extended to treat diseases such as cancer, CNS disorder, diabetes and dementia. ${ }^{1}$ Due to their distinct physicochemical properties, sulfonamides have been used extensively as bioisosteres of carboxylic acids and carboxamides. ${ }^{2}$ Also, the possibility of finetuning $\mathrm{p} K_{\mathrm{a}}$ values through modification of the sulfonamide $\mathrm{NH}$-substituent, has made them powerful functionalities to improve on drug potency and efficacy. ${ }^{2 \mathrm{a}, 3}$ Traditional approaches towards sulfonamides consist of reacting sulfonyl chlorides with amines. ${ }^{4}$ More recently, alternative procedures have been developed to access (hetero)arylsulfonamides. ${ }^{5}$ For example, Willis and co-workers developed a $\mathrm{Cu}$-catalyzed protocol allowing the attachment of $\mathrm{SO}_{2} \mathrm{~N}$-functionality to (hetero)aryl and alkenyl boronic acids using DABSO, a surrogate reagent for $\mathrm{SO}_{2}{ }^{6}$ In the same year, a photosensitized nickel catalyzed cross-coupling between $N$-(hetero)aryl sulfonamide and $N$-(hetero)aryl bromides was reported by MacMillan and co-workers providing a broad range of arylsulfonamide motifs. ${ }^{7}$ Methods to access alkylsulfonamides have also appeared due to the increasing demand from the pharmaceutical sector for $\mathrm{C}\left(\mathrm{sp}^{3}\right)$-rich molecules. ${ }^{8}$ Most syntheses reported to date require a multiple reactions sequence, whereby an alkene is converted to a thioether or thioester, oxidized to a sulfonyl chloride, and subjected to amination. ${ }^{9}$ This sequence suffers from limited functional group tolerance due to the harsh reaction conditions applied in the steps involved. To overcome these challenges, Noël and co-workers recently described the electrochemical oxidative coupling between alkyl thiols and amines (Scheme 1A). ${ }^{10}$

The aim of this study was to provide facile access to alkylsulfonamides from inexpensive feedstock olefins applying a single-step hydrosulfamoylation with sulfamoyl chlorides, many being commercially available. ${ }^{11}$ This late-stage functionalization process was viewed as advantageous to accelerate access to diverse chemical libraries for immediate impact on drug discovery.

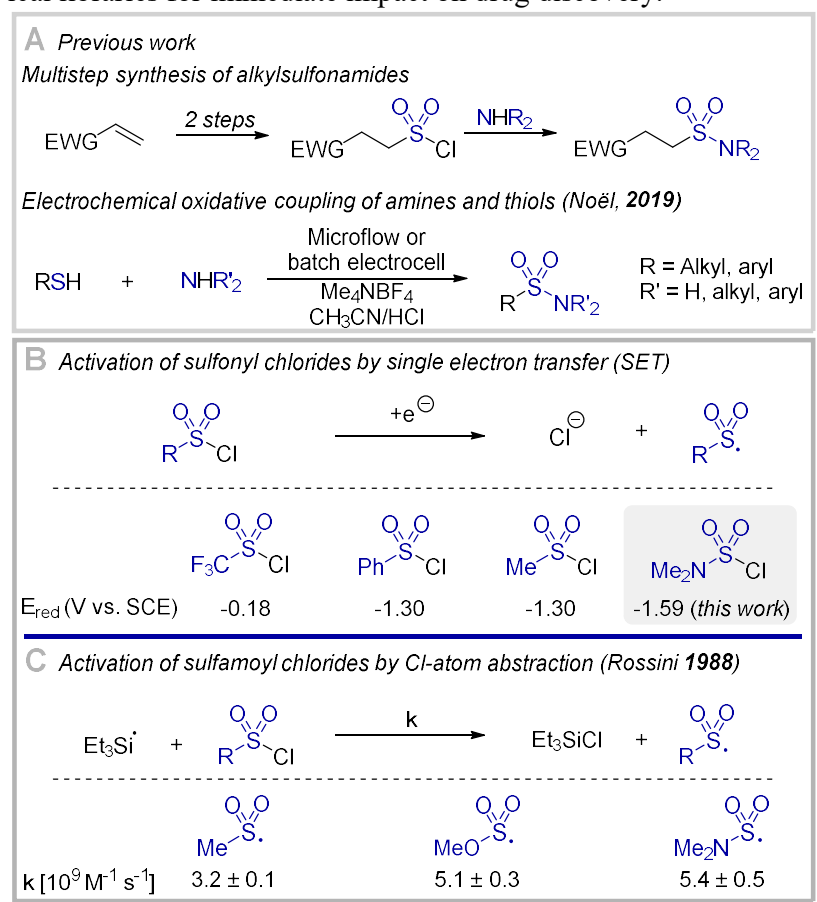

Scheme 1. A. Synthesis of alkylsulfonamides. B. Activation of sulfonyl chlorides by single electron transfer (SET). C. Activation of sulfamoyl chlorides by $\mathrm{Cl}$-atom abstraction. $\mathrm{EWG}=$ electron-withdrawing group.

Photoredox catalysis has gained considerable interest for the functionalization of $\mathrm{C}\left(\mathrm{sp}^{3}\right)$-centers. ${ }^{12}$ These advances include the generation of sulfonyl radicals from sulfonyl chlorides for subsequent addition to alkenes. ${ }^{13}$ The success of these transformations relies on a redox matching between the excited state of the photocatalyst and the sulfonyl chloride. Fluoroalkyl, alkyl as well as (hetero)aryl sulfonyl chlorides have been successfully activated by single electron reduction. ${ }^{13,14}$ However, the generation of sulfamoyl radicals from sulfamoyl chlorides remains underexplored. ${ }^{13 c, e, 15}$

Preliminary work indicated that the direct single electron reduction of dimethylsulfamoyl chloride $\left(\mathrm{E}_{\mathrm{red}}=-1.59 \mathrm{~V}\right.$ vs. saturated 
calomel electrode (SCE) in $\mathrm{MeCN})^{16}$ is more challenging than for methanesulfonyl chloride (Scheme 1B). An alternative pathway for the generation of sulfamoyl radical is therefore desirable. Electron Paramagnetic Resonance (EPR) studies conducted by Rossini and co-workers, demonstrated in 1988 that dimethylsulfamoyl and methylsulfonyl radicals can be generated via direct Cl-atom abstraction by a silyl radical with similar reaction rates $\left(\sim 10^{9} \mathrm{M}^{-1} \mathrm{~s}^{-1}\right)$ (Scheme 1C). ${ }^{17}$ With this knowledge, we designed a mechanistic scenario enabling hydrosulfamoylation of alkenes, whereby a silyl radical formed by photoredox catalysis would abstract a $\mathrm{Cl}$-atom from a sulfamoyl chloride to afford a sulfamoyl radical, which could add to an alkene (Scheme 2). ${ }^{18}$ Upon light irradiation, photocatalyst Eosin Y (PC) should produce excited triplet state PC* that could undergo single-electron transfer (SET) $\left[\mathrm{E}_{1 / 2}{ }^{\text {red }}\left(\mathrm{PC}^{*} / \mathrm{PC}^{--}\right)=+0.83 \mathrm{~V}\right.$ versus saturated calomel electrode $(\mathrm{SCE})]^{12 \mathrm{~b}} \quad$ with tris(trimethylsilyl)silane $\quad$ (TTMSS) $\left[E^{\text {ox }}\left(\mathrm{TTMSS}^{\mathrm{TTTMSS}}{ }^{+}\right)=+0.73 \mathrm{~V} \text { vs SCE}\right]^{18 \mathrm{~d}}$ to generate the Sicentered radical $\mathbf{A}$ upon loss of a proton. Radical $\mathbf{A}$ would abstract the $\mathrm{Cl}$-atom from sulfamoyl chloride affording sulfamoyl radical $\mathbf{B}$ that could undergo regioselective Giese addition to the alkene leading to the $\mathrm{C}$-centered radical C. A single electron reduction event would afford the hydrosulfamoylated product and concomitantly regenerate Eosin Y (Scheme 2, Path A). An alternative photoinitiation-radical chain propagation pathway involving direct $\mathrm{H}$-atom abstraction from TTMSS is also possible (Scheme 2, Path B).

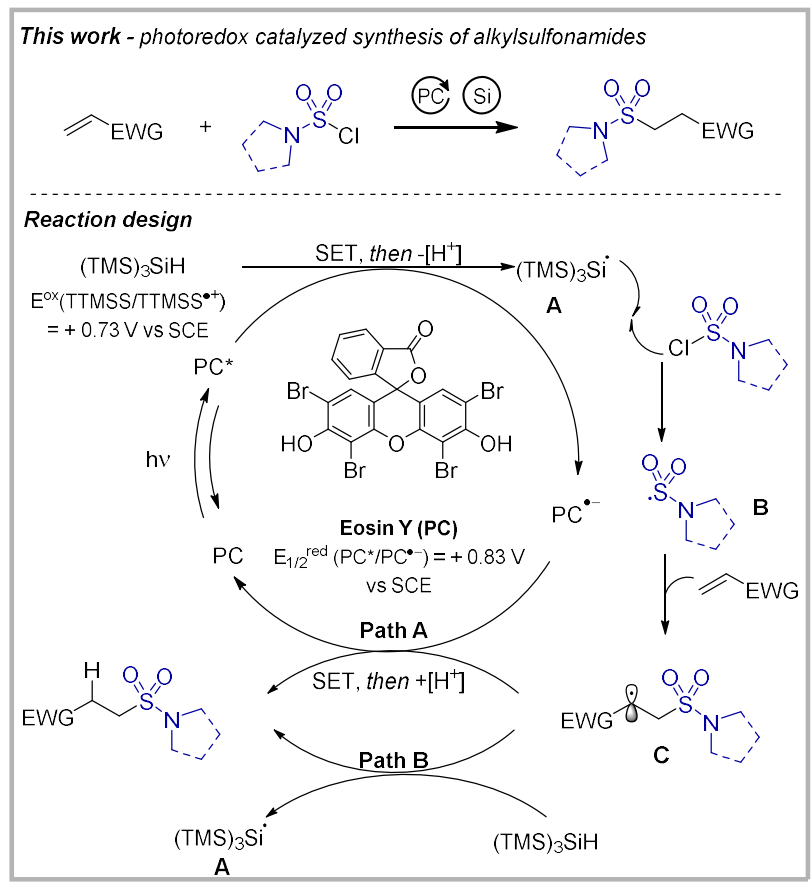

Scheme 2: Photoredox-catalyzed hydrosulfamoylation of electron-deficient alkenes. $\mathrm{EWG}=$ electron-withdrawing group $. \mathrm{PC}=$ photocatalyst. $\mathrm{Si}$ $=$ tris(trimethylsilyl)silane.

A range of experiments revealed that treatment of $\mathrm{N}$ phenylacrylamide 1a with Eosin Y (0.5 mol\%), (TMS $)_{3} \mathrm{SiH}$, dimethylsulfamoyl chloride 2a and $\mathrm{MeCN}$ as solvent under blue LED irradiation $\left(\lambda_{\max }=470 \mathrm{~nm}\right)$, afforded the desired hydrosulfamoylated product 3a isolated in $83 \%$ yield (Table 1 , entry 1). A lower efficiency was observed when using different catalyst loadings or solvents (Table 1, entries 2-5). Notably, employment of silanes other than (TMS $)_{3} \mathrm{SiH}$ failed to produce $\mathbf{3 a}$ (Table 1, entries 6-7) ${ }^{18 \mathrm{a}, \mathrm{d}, \mathrm{g}}$ Iridium-based

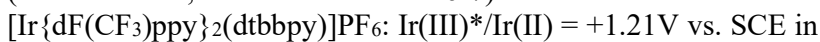
$\mathrm{MeCN})$ and ruthenium-based $\left(\mathrm{Ru}(\mathrm{bpy})_{3}\left(\mathrm{PF}_{6}\right)_{2}: \mathrm{Ru}(\mathrm{II}) * / \mathrm{Ru}(\mathrm{I})=\right.$ $+0.77 \mathrm{~V}$ vs. SCE in $\mathrm{MeCN}$ ) photocatalysts were found to be suitable
Table 1. Range of experiments for the hydrosulfamoylation of alkenes. ${ }^{[a]}$

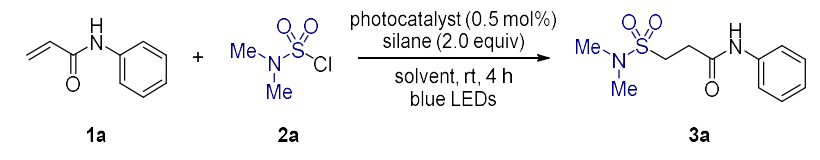

\begin{tabular}{|c|c|c|c|c|}
\hline entry & photocatalyst & silane & solvent & yield [\%] \\
\hline 1 & Eosin Y & $(\mathrm{TMS})_{3} \mathrm{SiH}$ & $\mathrm{MeCN}$ & 83 \\
\hline $2^{[b]}$ & Eosin $Y$ & $(\mathrm{TMS})_{3} \mathrm{SiH}$ & $\mathrm{MeCN}$ & 69 \\
\hline $3^{[\mathrm{c}]}$ & Eosin $Y$ & $(\mathrm{TMS})_{3} \mathrm{SiH}$ & $\mathrm{MeCN}$ & 73 \\
\hline 4 & Eosin $Y$ & $(\mathrm{TMS})_{3} \mathrm{SiH}$ & DCE & 14 \\
\hline 5 & Eosin $Y$ & $(\mathrm{TMS})_{3} \mathrm{SiH}$ & DMF & 45 \\
\hline 6 & Eosin $Y$ & $\mathrm{Et}_{3} \mathrm{SiH}$ & $\mathrm{MeCN}$ & 0 \\
\hline 7 & Eosin Y & $\mathrm{Ph}_{3} \mathrm{SiH}$ & $\mathrm{MeCN}$ & 0 \\
\hline 8 & $\begin{array}{l}{\left[\operatorname{Ir}\left\{\mathrm{dF}\left(\mathrm{CF}_{3}\right) \mathrm{ppy}\right\}_{2}(\mathrm{dtbbpy}\right.} \\
)] \mathrm{PF}_{6}\end{array}$ & $(\mathrm{TMS})_{3} \mathrm{SiH}$ & $\mathrm{MeCN}$ & 88 \\
\hline 9 & $\mathrm{Ru}(\mathrm{bpy})_{3}\left(\mathrm{PF}_{6}\right)_{2}$ & $(\mathrm{TMS})_{3} \mathrm{SiH}$ & $\mathrm{MeCN}$ & 74 \\
\hline 10 & Eosin $Y$ & - & $\mathrm{MeCN}$ & 0 \\
\hline $11^{[\mathrm{d}]}$ & Eosin $Y$ & $(\mathrm{TMS})_{3} \mathrm{SiH}$ & $\mathrm{MeCN}$ & 0 \\
\hline 12 & - & $(\mathrm{TMS})_{3} \mathrm{SiH}$ & $\mathrm{MeCN}$ & $0^{[\mathrm{e}]}$ \\
\hline $13^{[\mathrm{f}]}$ & Eosin $Y$ & $(\mathrm{TMS})_{3} \mathrm{SiH}$ & $\mathrm{MeCN}$ & $0^{[\mathrm{g}]}$ \\
\hline $14^{[\mathrm{h}]}$ & Eosin $Y$ & $(\mathrm{TMS})_{3} \mathrm{SiH}$ & $\mathrm{MeCN}$ & 0 \\
\hline
\end{tabular}

[a] Reaction conditions: 1a $(0.5 \mathrm{mmol}), \mathbf{2 a}(1.25 \mathrm{mmol})$, photocatalyst $(0.5 \mathrm{~mol} \%)$, silane $(1.0 \mathrm{mmol})$, solvent $(3.0 \mathrm{~mL})$ under blue light $\left(\lambda_{\max }=\right.$ $470 \mathrm{~nm}$ ) irradiation for $4 \mathrm{~h}$. Yields of isolated products. [b] $1 \mathrm{~mol} \%$ of Eosin Y was used. [c] $0.1 \mathrm{~mol} \%$ of Eosin Y was used. [d] Reaction performed in the dark. [e] After $16 \mathrm{~h}, 80 \%$ of $\mathbf{3 a}$ was isolated. [f] no sulfamoyl chloride 2a was added. [g] 74\% of hydrosilylated product was isolated. [h] 4.0 equiv of TEMPO ((2,2,6,6-tetramethylpiperidin-1yl)oxyl) were added. $\left[\operatorname{Ir}\left\{\mathrm{dF}\left(\mathrm{CF}_{3}\right) \text { ppy }\right\}_{2}(\mathrm{dtbbpy})\right] \mathrm{PF}_{6}=\left[4,4^{\prime}-\mathrm{Bis}(1,1-\mathrm{di}-\right.$ methylethyl)-2,2'-bipyridine-N1,N1']bis[3,5-difluoro-2-\{5-(trifluoromethyl)-2-pyridinyl-N\}phenyl-C]Iridium(III) hexafluorophosphate. $\mathrm{Ru}(\mathrm{bpy})_{3}\left(\mathrm{PF}_{6}\right)_{2}=\operatorname{Tris}\left(2,2^{\prime}\right.$-bipyridine)ruthenium(II) hexafluorophosphate.

for this transformation (Table 1, entries 8-9). ${ }^{12 a}$ Eosin $\mathrm{Y}$ was retained for further studies due to economic and ecological considerations. Control experiments demonstrated that irradiation and (TMS) ${ }_{3} \mathrm{SiH}$ are essential for this transformation (Table 1, entries 10,11). The reaction can be performed without photocatalyst, although this process requires significantly longer reaction time (Table 1, entry 12; 16 hours instead of 4 hours). In absence of sulfamoyl chloride, the hydrosilylated product was isolated in good yield, demonstrating the ability of Eosin $\mathrm{Y}$ to generate a silyl radical from TTMSS (Table 1, entry 13). ${ }^{19}$ Furthermore, full recovery of starting material was observed when the radical scavenger TEMPO ((2,2,6,6-tetramethylpiperidin-1yl)oxyl) was added to the standard reaction conditions (Table 1 , entry 14). Finally, no deuterium incorporation was observed using $\mathrm{MeCN}-d_{3}$ as solvent or by addition of excess MeOD, suggesting that TTMSS acts as a $\mathrm{H}$-atom donor. (TMS) ${ }_{3} \mathrm{SiCl}$ was isolated as a side-product of the reaction, which is consistent with $\mathrm{Cl}$-atom abstraction from the silyl radical. The results of the deuteration experiments and the observation that the reaction is possible in the absence of photocatalyst although more effective in its presence (Table 1, entry 12), advocate in favour of a photoinitiation-radical chain propagation pathway (Scheme 2, Path B).

With the optimized conditions in hand, we explored the generality of this transformation on a range of sulfamoyl chlorides as well as electron-deficient alkenes (Schemes 3 and 4). Various functional groups, such as esters, amides, carboxylic acids, amines, ethers, halides, nitro and nitriles were tolerated, and products 3a-ae were isolated in moderate to excellent yields. As shown in Scheme 3 , we established that primary, secondary as well as tertiary 
sulfamoyl chlorides are suitable precursors for the hydrosulfamoylation of $\mathrm{N}$-phenylacrylamide (1a). Dimethyl, diethyl and bis(2-methoxyethyl)sulfamoyl chloride (2a-c) allowed the introduction of linear sulfonamides in good yields. Benzylmethylsulfamoyl choride (2d) was successfully used for this transformation and afforded $\mathbf{3 d}$ in $75 \%$ yield. The incorporation of cyclic sulfonamides including five-, six- and seven-membered rings afforded pyrrolidine, piperidine and azepane sulfonamides in good to excellent yields (3e-g). A sulfonamide containing a morpholine moiety was isolated in $82 \%$ yield $(\mathbf{3 h})$. Piperidine derivatives containing an ester and a nitrile, as well as a 3-methoxymethylpyrrolidine were compatible with this protocol allowing access to valuable building blocks containing vectors for further functionalization (3ik). Furthermore, sulfamoyl chlorides containing small rings of pharmaceutical relevance, decorated with fluorine and methoxy substituents were also competent substrates $(\mathbf{3 l}, \mathbf{m})$. Additionally, a secondary sulfonamide was obtained in moderate yield (3n). Sulfamoyl chloride proved to be a suitable reagent and afforded the primary sulfonamide in $46 \%$ yield (3o), a motif commonly used in bioactive molecules..$^{20}$
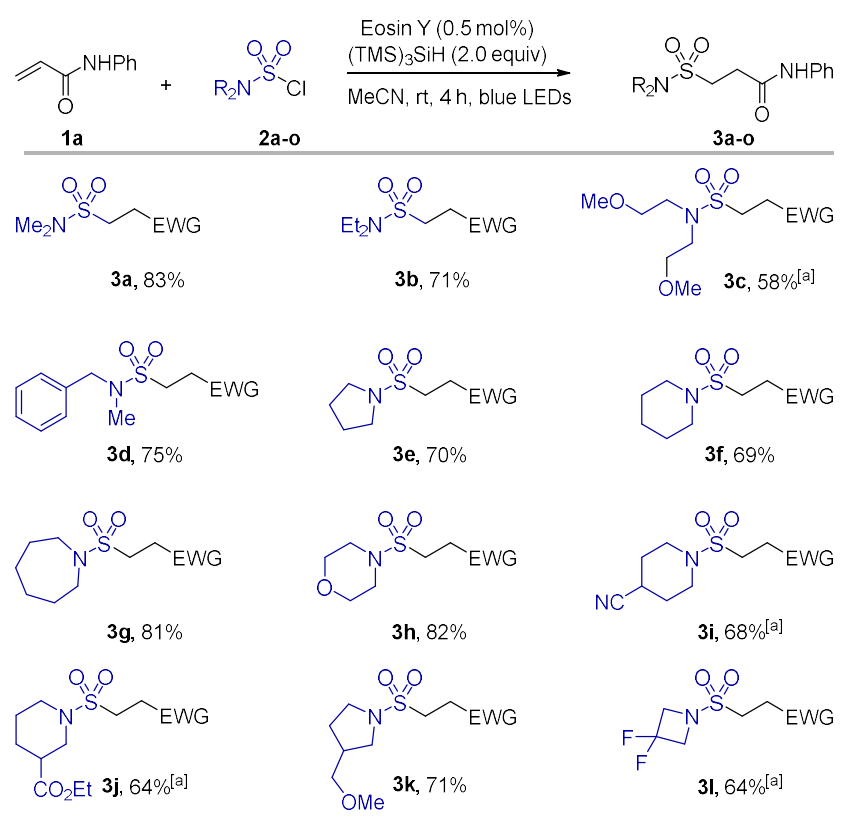

$$
\text { 30, } 46 \% \%^{[a]}
$$$$
\mathcal{M e O}^{N^{\text {SIS }}}
$$$$
\text { Me. }
$$

Scheme 3. Substrate scope of sulfamoyl chlorides. Reaction conditions: alkene $1 \mathrm{a}(0.5 \mathrm{mmol}), \mathbf{2 a - 0}(1.25 \mathrm{mmol})$, TTMSS $(1.0 \mathrm{mmol})$, Eosin Y $(0.5$ $\mathrm{mol} \%), \operatorname{MeCN}(3.0 \mathrm{~mL})$, blue LED irradiation $\left(\lambda_{\max }=470 \mathrm{~nm}\right)$, room temperature, $4 \mathrm{~h}$. Yields of isolated products. [a] $16 \mathrm{~h}$ reaction time. $\mathrm{EWG}=$ $\mathrm{C}(\mathrm{O}) \mathrm{NHPh}$.

We next examined the scope of electron-deficient alkenes using dimethylsulfamoyl chloride (Scheme 4). A variety of $N$-phenylacrylamides bearing different substituents on the arene were initially surveyed. Both electron-withdrawing and -donating groups, such as halogen, nitro, nitrile and methoxy, were tolerated and afforded the desired products in good yields (3p-s). Notably, the reaction of substrates 1c-e was significantly slower (16 hours reaction time). Photocatalyst $\left[\operatorname{Ir}\left\{\mathrm{dF}\left(\mathrm{CF}_{3}\right) \mathrm{ppy}\right\}_{2}(\mathrm{dtbbpy})\right] \mathrm{PF}_{6}$ was more effective (4 hours reaction time). Heteroarenes, such as the pyridine derivative was converted to the hydrosulfamoylated product with no competitive C-H sulfamoylation (3t). Ketone and ester derivatives were transformed to the desired products in good yields $(3 \mathbf{v}, \mathbf{w})$. Considering the high value of cyclobutane derivatives to medicinal chemists, we investigated the introduction of sulfonamide function into cyclobutenes. ${ }^{21}$ Highly valuable 1,2-disubstituted cyclobutanes were isolated in moderate yield and diastereomeric ratio $(\mathbf{3 x}, \mathbf{y})$, a useful advance considering that radical functionalization of cyclobutenes remains underexplored; this is possibly due to their propensity to undergo $4 \pi$-electrocyclic ring opening as well as polymerization. ${ }^{22} \mathrm{Gem}$-disubstituted alkenes afforded the hydrosulfamoylated products in good yield $(\mathbf{3 z}, \mathbf{a a})$. A representative electron-deficient alkyne gave the desired hydrosulfamoylated alkene with high Z-selectivity (Z/E: 90/10) and good yield (3ab). We noted competitive desulfonylation with $N$-benzylmaleimide (3ac). ${ }^{23}$ Unactivated and electron-rich alkenes do not react under our reaction conditions. ${ }^{16}$

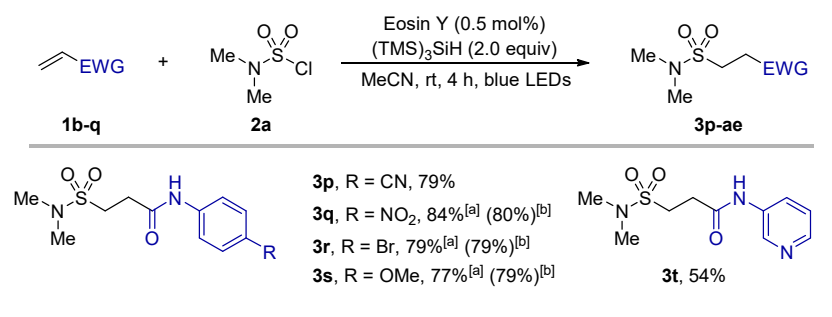<smiles>CN(C)S(=O)(=O)CCC(=O)Nc1nc2ccccc2s1</smiles><smiles>CN(C)S(=O)(=O)CCC(=O)c1ccccc1</smiles><smiles>CCCCCOC(=O)CCS(=O)(=O)N(C)C</smiles><smiles>CN(C)S(=O)(=O)C1CCC1C(=O)Oc1ccccc1</smiles>

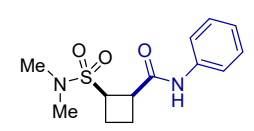
$3 \mathbf{w}, 91 \%(80 \%)^{[c]}$

$$
\text { 3aa, } 71 \%
$$$$
3 y, 84 \% \text { (d.r: } 50 / 50)^{[d]}
$$$$
M e^{\prime} \stackrel{M}{N}=00
$$$$
\text { 3ab, 61\% (Z/E: 90/10) })^{[\mathrm{ee}}
$$<smiles>[Y4]C(CS(=O)(=O)N(C)C)C(=O)OC</smiles>

$3 \mathbf{z}, 61 \%$<smiles>CN(C)C1CC(=O)N(Br)C1=O</smiles>

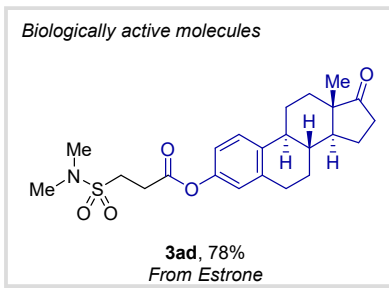<smiles>CN(C)S(=O)(=O)CCC(=O)N1CCCC(n2nc(-c3ccc(Oc4ccccc4)cc3)c3c(N)ncnc32)C1</smiles>

Scheme 4. Substrate scope of electron-deficient alkenes. Reaction conditions: alkene 1b-q $(0.5 \mathrm{mmol}), \mathbf{2 a}(1.25 \mathrm{mmol})$, TTMSS $(1.0 \mathrm{mmol})$, Eosin $\mathrm{Y}(0.5 \mathrm{~mol} \%), \mathrm{MeCN}(3.0 \mathrm{~mL})$, blue LED irradiation $\left(\lambda_{\max }=470 \mathrm{~nm}\right)$, room temperature, $4 \mathrm{~h}$. Yields of isolated products. [a] $16 \mathrm{~h}$ reaction time. [b] $\left[\operatorname{Ir}\left\{\mathrm{dF}\left(\mathrm{CF}_{3}\right) \text { ppy }\right\}_{2}(\mathrm{dtbbpy})\right] \mathrm{PF}_{6}$ was used instead of Eosin $\mathrm{Y}$ and full conversion was observed within 4 hours. [c] Scale-up experiment performed on $30.8 \mathrm{mmol}$ (5.0 g) of benzyl acrylate. [d] The diastereomers were separated by silica flash column chromatography. [e] The minor isomer was not isolated. [f] Only traces of the hydrosulfamoylated product was observed.

To further demonstrate the potential of this transformation to late-stage functionalization, we applied this methodology to the derivatization of alkene-containing biologically active molecules. A hydrosulfamoylated Estrone derivative was isolated in good yield (3ad). Furthermore, hydrosulfamoylation of Ibrutinib afforded 3ae in good yield, with all functional groups other than the alkene remaining intact. The hydrosulfamoylation of benzyl acrylate $1 \mathbf{i}$ was accomplished in one step on a $5 \mathrm{~g}$ scale affording $\mathbf{3 w}$ in $80 \%$ yield $(6.7 \mathrm{~g})$, suggesting that this methodology could be 
applicable to large-scale batch production. Further transformations of $\mathbf{3 w}$ included hydrolysis, reduction and amidation. ${ }^{16}$

We explored the possibility to build molecular complexity through intramolecular quaternization of the $\alpha$-carbonyl radical intermediate. ${ }^{24} \mathrm{~N}$-Methyl- $\mathrm{N}$-phenylcyclobutene carboxamide $1 \mathbf{r}$ underwent a cascade spirocyclization to afford sulfonamide-containing cyclobutyl-spirooxindoles (4a-c). Both Eosin Y and $\left[\operatorname{Ir}\left\{\mathrm{dF}\left(\mathrm{CF}_{3}\right) \text { ppy }\right\}_{2}(\mathrm{dtbbpy})\right] \mathrm{PF}_{6}$ were suitable photocatalysts, but the Ir photocatalyst gave higher yields. Linear, cyclic as well as heterocyclic sulfonamides were within reach albeit in low diastereoselectivity; these were easily separated affording valuable 3Dbuilding blocks for medicinal chemistry (Scheme 5). ${ }^{25}$

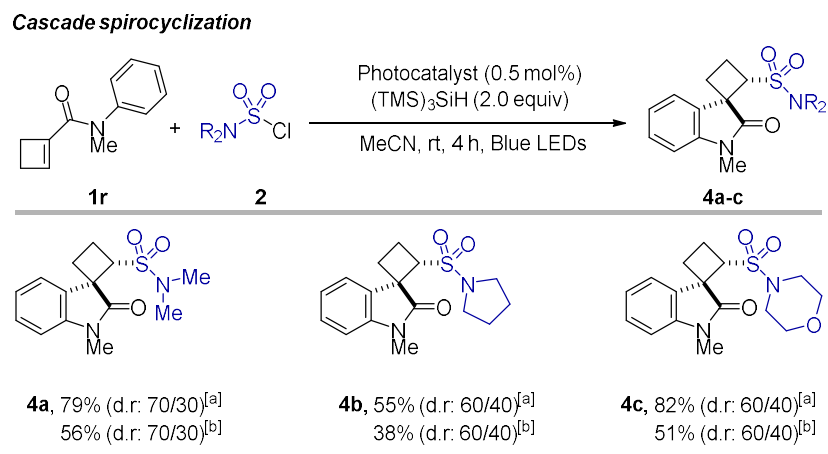

Scheme 5. Substrate scope of sulfonamide-containing cyclobutylspirooxindoles. Reaction conditions: $1 \mathbf{r}(0.5 \mathrm{mmol}), 2$ (1.25 mmol), TTMSS (1.0 $\mathrm{mmol})$, photocatalyst $(0.5 \mathrm{~mol} \%), \mathrm{MeCN}(3.0 \mathrm{~mL})$, blue LED irradiation $\left(\lambda_{\max }=470 \mathrm{~nm}\right)$, room temperature, $4 \mathrm{~h}$. Yields of isolated products. Both diastereomers were separated by silica flash column chromatography. [a] $\left[\operatorname{Ir}\left\{\mathrm{dF}\left(\mathrm{CF}_{3}\right) \text { ppy }\right\}_{2}(\mathrm{dtbbpy})\right] \mathrm{PF}_{6}$ as photocatalyst. [b] Eosin $\mathrm{Y}$ as photocatalyst.

In conclusion, this study established that tris(trimethylsilyl)silane enables facile hydrosulfamoylation of alkenes by serving both as a silyl radical source capable of activating sulfamoyl chlorides, and as the hydrogen atom donor. This most practical and cost-effective methodology is performed in the presence of the organophotocatalyst Eosin Y. Numerous functional groups are tolerated allowing access to a broad range of novel alkylsulfonamides that are valuable building blocks for drug discovery.

\section{ASSOCIATED CONTENT}

\section{Supporting Information}

The Supporting Information is available free of charge on the ACS Publications website.

Data and materials availability: additional optimization, mechanistic data, cyclic voltammetry, experimental procedures and analytical data $\left({ }^{1} \mathrm{H},{ }^{19} \mathrm{~F},{ }^{13} \mathrm{C}\right.$ NMR, high resolution mass spectrometry) for all new compounds (PDF).

\section{AUTHOR INFORMATION}

\section{Corresponding Author}

veronique.gouverneur@chem.ox.ac.uk

\section{Notes}

The authors declare no competing financial interests.

\section{ACKNOWLEDGMENT}

We gratefully acknowledge Dr Maurice Médebielle for insightful comments on the manuscript, and Dr Natan Straathof and Tim Mollner for discussions. This project has received funding from the
European Union's Horizon 2020 research and innovation programme under the Marie Skłodowska-Curie grant agreement No 721902. T.N. and G.L. acknowledge financial support from the Dutch Science Foundation (NWO) (VIDI, SensPhotoFlow, No. 14150).

\section{REFERENCES}

(1) a) Wainwright, M.; Kristiansen, J. E. On the $75^{\text {th }}$ anniversary of Prontosil. Dyes Pigments 2011, 88, 231-234; b) Zaffiri, L.; Gardner, J.; ToledoPereyra, L. H. History of antibiotics. From Salvarsan to Cephalosporins. J. Invest. Surg. 2012, 25, 67-77; c) Feng, M.; Tang, B.; Liang, S. H.; Jiang, $\mathrm{X}$. Sulfur Containing Scaffolds in Drugs: Synthesis and Application in Medicinal Chemistry. Curr. Top. Med. Chem. 2016, 16, 1200-1216; d) Scott, K. A.; Njardarson, J. T. Analysis of US FDA-Approved Drugs Containing Sulfur Atoms. In: Jiang, X. (ed) Sulfur Chemistry. Topics in Current Chemistry Collections. Springer, Cham, 2018; e) Drews, J. Drug discovery: a historical perspective. Science 2000, 287, 1960-1964; f) Casini, A.; Scozzafava, A.; Mastrolorenzo, A.; Supuran, C. T. Sulfonamides and Sulfonylated Derivatives as Anticancer Agents. Curr. Cancer Drug Tar. 2002, 2, 55-75; g) Kalgutkar, A. S.; Jones, R.; Sawant, A. Sulfonamide as an Essential Functional Group in Drug Design. In: Smith, D. A. (ed) Metabolism, Pharmacokinetics and Toxicity of Functional Groups: Impact of Chemical Building Blocks on ADMET, Royal Society of Chemistry, Cambridge, 2010; h) Shah, S. A.; Rivera, G.; Ashfaq, M. Recent Advances in Medicinal Chemistry of Sulfonamides. Rational Design as Anti-Tumoral, Anti-Bacterial and Anti-Inflammatory Agents. Mini-Reviews in Medicinal Chemistry 2013, 13, 70-86; i) Smith, B. R.; Eastman, C. M.; Njardarson, J. T. Beyond C, H, O, and N! Analysis of the Elemental Composition of U.S. FDA Approved Drug Architectures. J. Med. Chem. 2014, 57, 9764-9773; j) Ilardi, E. A.; Vitaku, E.; Njardarson, J. T. Data-Mining for Sulfur and Fluorine: An Evaluation of Pharmaceuticals To Reveal Opportunities for Drug Design and Discovery. J. Med. Chem. 2014, 57, 2832-2842; k) Bag, S.; Tulsan, R.; Sood, A.; Cho, H.; Redjeb, H.; Zhou, W.; LeVine III, H.; Török, B.; Török, M. Sulfonamides as multifunctional agents for Alzheimer's disease. Bioorg. Med. Chem. Lett. 2015, 25, 626-630; 1) Gao, H.-D.; Liu, P.; Yang, Y.; Gao, F. Sulfonamide-1,3,5-triazine-thiazoles: discovery of a novel class of antidiabetic agents via inhibition of DPP-4. RSC Adv. 2016, 6, 83438-83447; m) Apaydın, S.; Török, M. Sulfonamide derivatives as multi-target agents for complex diseases. Bioorg. Med. Chem. Lett. 2019, 29, 2042-2050.

(2) a) Pinter, T.; Jana, S.; Courtemanche, R. J. M.; Hof, F. Recognition Properties of Carboxylic Acid Bioisosteres: Anion Binding by Tetrazoles, Aryl Sulfonamides, and Acyl Sulfonamides on a Calix[4]arene Scaffold. J. Org. Chem. 2011, 76, 3733-3741; b) Ballatore, C.; Huryn, D. M.; Smith III, A. B. Carboxylic Acid (Bio)Isosteres in Drug Design. ChemMedChem 2013, 8, 385-395; c) Lassalas, P.; Gay, B.; Lasfargeas, C.; James, M. J.; Tran, V.; Vijayendran, K. G.; Brunden, K. R.; Kozlowski, M. C.; Thomas, C. J.; Smith III, A. B.; Huryn, D. M.; Ballatore, C. Structure Property Relationships of Carboxylic Acid Isosteres. J. Med. Chem. 2016, 59, 31833203.

(3) Şanli, N.; Şanli, S.; Özkan, G.; Denizlic, A. Determination of $\mathrm{p} K_{\mathrm{a}}$ values of some sulfonamides by LC and LC-PDA methods in acetonitrile-water binary mixtures. J. Braz. Chem. Soc. 2010, 21, 1952-1960.

(4) a) Bahrami, K.; Khodaei, M. M.; Soheilizad, M. Direct Conversion of Thiols to Sulfonyl Chlorides and Sulfonamides. J. Org. Chem. 2009, 74, 9287-9291; b) Veisi, H.; Ghorbani-Vaghei, R.; Hemmati, S.; Mahmoodi, J. Convenient One-Pot Synthesis of Sulfonamides and Sulfonyl Azides from Thiols Using $N$-Chlorosuccinimide. Synlett, 2011, 16, 2315-2320.

(5) a) Yin, J.; Buchwald, S. L. Palladium-Catalyzed Intermolecular Coupling of Aryl Halides and Amides. Org. Lett. 2000, 2, 1101-1104; b) Burton, G.; Cao, P.; Li, G.; Rivero, R. Palladium-Catalyzed Intermolecular Coupling of Aryl Chlorides and Sulfonamides under Microwave Irradiation. Org. Lett. 2003, 5, 4373-4376; c) Shaabani, A.; Soleimani, E.; Rezayan, A. H. A novel approach for the synthesis of alkyl and aryl sulfonamides. Tetrahedron Lett. 2007, 48, 2185-2188; d) Baffoe, J.; Hoe, M. Y.; Touré, B. B. Copper-Mediated $N$-Heteroarylation of Primary Sulfonamides: Synthesis of Mono- $N$-heteroaryl Sulfonamides. Org. Lett. 2010, 12 , 1532-1535; e) DeBergh, J. R.; Niljianskul, N.; Buchwald, S. L. Synthesis of Aryl Sulfonamides via Palladium-Catalyzed Chlorosulfonylation of Arylboronic Acids. J. Am. Chem. Soc. 2013, 135, 10638-10641; f) Yang, B.; Lian, C.; Yue, G.; Liu, D.; Wei, L.; Ding, Y.; Zheng, X.; Lu, K.; Qiu, D.; Zhao, X. Synthesis of $N$-arylsulfonamides through a Pd-catalyzed reduction coupling reaction of nitroarenes with sodium arylsulfinates. Org. Biomol. Chem. 2018, 16, 8150-8154. 
(6) Chen, Y.; Murray, P. R. D.; Davies, A. T.; Willis, M. C. Direct Copper-Catalyzed Three-Component Synthesis of Sulfonamides. J. Am. Chem. Soc. 2018, 140, 8781-8787.

(7) Kim, T.; McCarver, S. J.; Lee C.; MacMillan, D. W. C. Sulfonamidation of Aryl and Heteroaryl Halides through Photosensitized Nickel Catalysis. Angew. Chem. Int. Ed. 2018, 57, 3488-3492.

(8) a) Goldberg, F. W.; Kettle, J. G.; Kogej, T.; Perry, M. W. D.; Tomkinson, N. P. Designing novel building blocks is an overlooked strategy to improve compound quality. Drug Discov. Today 2015, 20, 11-17; b) Lovering, F.; Bikker, J.; Humblet, C. Escape from Flatland: Increasing Saturation as an Approach to Improving Clinical Success. J. Med. Chem. 2009, 52, 6752-6756; c) Lovering, F. Escape from Flatland 2: complexity and promiscuity. Med. Chem. Commun. 2013, 4, 515-519.

(9) a) Chan, W. Y.; Berthelette, C. A mild, efficient method for the synthesis of aromatic and aliphatic sulfonamides. Tetrahedron Lett. 2002, 43, 4537-4540; b) Burrows, J. N.; Tucker, H. 1-Sulphonyl piperidine derivatives. WO 2004/024698A1, 2004; c) Burns, D. M.; Yao, W.; He, C. Hydroxamic acid derivatives as metalloprotease inhibitors. WO 2005/117882A2, 2005; d) Cumming, J. N.; Gilbert, E. J.; Stamford, A. W. C5-c6 oxacyclic-fused thiadiazine dioxide compounds as BACE inhibitors, compositions, and their use. WO 2012/138734A1, 2012. e) Joyard, Y.; Papamicaël, C.; Bohn, P.; Bischoff, L. Synthesis of Sulfonic Acid Derivatives by Oxidative Deprotection of Thiols Using tert-Butyl Hypochlorite. Org. Lett., 2013, 15, 2294-2297; f) Shavnya, A.; Coffey, S. B.; Hesp, K. D.; Ross, S. C.; Tsai, A. S. Reaction of Alkyl Halides with Rongalite: One-Pot and Telescoped Syntheses of Aliphatic Sulfonamides, Sulfonyl Fluorides, and Unsymmetrical Sulfones. Org. Lett. 2016, 18, 5848-5851.

(10) Laudadio, G.; Barmpoutsis, E.; Schotten, C.; Struik, L.; Govaerts, S.; Browne, D. L.; Noël, T. Sulfonamide Synthesis through Electrochemical Oxidative Coupling of Amines and Thiols. J. Am. Chem. Soc. 2019, 141, $5664-5668$.

(11) For recent late-stage hydrofunctionalizations of alkenes see: a) Mizuta, S.; Verhoog, S.; Engle, K. M.; Khotavivattana, T.; O'Duill, M.; Wheelhouse, K.; Rassias, G.; Médebielle, M.; Gouverneur V. Catalytic Hydrotrifluoromethylation of Unactivated Alkenes. J. Am. Chem. Soc. 2013, 135, 2505-2508; b) Wilger, D. J.; Gesmundo, N. J.; Nicewicz, D. A. Catalytic hydrotrifluoromethylation of styrenes and unactivated aliphatic alkenes via an organic photoredox system. Chem. Sci., 2013, 4, 3160-3165; c) Nguyen, T. M.; Manohar, N.; Nicewicz, D. A. anti-Markovnikov Hydroamination of Alkenes Catalyzed by a Two-Component Organic Photoredox System: Direct Access to Phenethylamine Derivatives. Angew. Chem. Int. Ed. 2014, 53, 6198-6201; d) Chu, L; Ohta, C.; Zuo, Z.; MacMillan, D. W. C. Carboxylic Acids as A Traceless Activation Group for Conjugate Additions: A Three-Step Synthesis of $( \pm)$-Pregabalin. J. Am. Chem. Soc. 2014, 136, 10886-10889; e) Davies, J.; Booth, S. G.; Essafi, S.; Dryfe, R. A. W.; Leonori, D. Visible-Light-Mediated Generation of Nitrogen-Centered Radicals: Metal-Free Hydroimination and Iminohydroxylation Cyclization Reactions. Angew. Chem. Int. Ed. 2015, 54, 14017-14021; f) Simmons, B.; Walji, A. M.; MacMillan, D. W. C. Cycle-Specific Organocascade Catalysis: Application to Olefin Hydroamination, Hydro-oxidation, and Amino-oxidation, and to Natural Product Synthesis. Angew. Chem. Int. Ed. 2009, 48, 4349-4353; g) Davies, J.; Svejstrup, T. D.; Reina, D. F.; Sheikh, N. S.; Leonori D. Visible-Light-Mediated Synthesis of Amidyl Radicals: Transition-Metal-Free Hydroamination and $\mathrm{N}$-Arylation Reactions. J. Am. Chem. Soc. 2016, 138, 8092-8095; h) Meyer, C. F.; Hell, S. M.; Misale, A.; Trabanco, A. A.; Gouverneur, V. Hydrodifluoromethylation of Alkenes with Difluoroacetic Acid. Angew. Chem. Int. Ed. 2019, 58, 8829-8833; i) Meyer, C. F.; Hell, S. M.; Sap, J. B. I.; Misale, A.; Peschiulli, A.; Oehlrich, D.; Trabanco, A. A.; Gouverneur, V. Hydrochlorofluoromethylation of unactivated alkenes with chlorofluoroacetic acid. Tetrahedron 2019. Article 130679. doi.org/10.1016/j.tet.2019.130679.

(12) a) Prier, C. K.; Rankic, D. A.; MacMillan, D. W. C. Visible Light Photoredox Catalysis with Transition Metal Complexes: Applications in Organic Synthesis. Chem. Rev. 2013, 113, 5322-5363; b) Romero, N. A.; Nicewicz, D. A. Organic Photoredox Catalysis. Chem. Rev. 2016, 116, 10075-10166; c) Bogdos, M. K.; Pinard, E.; Murphy, J. A. Applications of organocatalysed visible-light photoredox reactions for medicinal chemistry. Beilstein J. Org. Chem. 2018, 14, 2035-2064; d) McAtee, R. C.; McClain, E. J.; Stephenson C. R. J. Illuminating Photoredox Catalysis. Trends Chem. 2019, $1,111-125$.

(13) a) Wallentin, C.-J.; Nguyen, J. D.; Finkbeiner, P.; Stephenson, C. R. J. Visible Light-Mediated Atom Transfer Radical Addition via Oxidative and Reductive Quenching of Photocatalysts. J. Am. Chem. Soc. 2012, 134, 8875-8884; b) Jiang, H.; Cheng, Y.; Zhang, Y.; Yu, S. Sulfonation and Trifluoromethylation of Enol Acetates with Sulfonyl Chlorides Using Visible-
Light Photoredox Catalysis. Eur. J. Org. Chem. 2013, 24, 5485-5492; c) Liu, X.; Cong, T.; Liu, P.; Sun, P. Visible light-promoted synthesis of 4(sulfonylmethyl)isoquinoline-1,3(2H,4H)-diones via a tandem radical cyclization and sulfonylation reaction. Org. Biomol. Chem. 2016, 14, 94169422; d) Pagire, S. K.; Paria, S.; Reiser, O. Synthesis of $\beta$-Hydroxysulfones from Sulfonyl Chlorides and Alkenes Utilizing Visible Light Photocatalytic Sequences. Org. Lett. 2016, 18, 2106-2109; e) Alkan-Zambada, M.; Hu, X. $\mathrm{Cu}$-Catalyzed Photoredox Chlorosulfonation of Alkenes and Alkynes. J. Org. Chem. 2019, 84, 4525-4533.

(14) a) Johansson, B. L.; Persson, B. Electrochemical Reduction of Aromatic Sulfenyl and Sulfonyl Chlorides. Acta Chem. Scand. Ser. B 1978, 32, 431-436; b) Ignat'ev, N.; Kucherina, A.; Sartori, P. Comparative Electrochemical Fluorination of Ethanesulfonyl Chloride and Fluoride. Acta Chem. Scand. 1999, 53, 1110-1116; c) Chaudhary, R.; Natarajan, P. Visible Light Photoredox Activation of Sulfonyl Chlorides: Applications in Organic Synthesis. ChemistrySelect 2017, 2, 6458-6479.

(15) a) Kharasch, M. S.; Mosher, R. A. Reactions of atoms and free radicals in solution. XXVIII. The addition of $N$-chlorosulfonylphtalimide to olefins. J. Org. Chem. 1952, 17, 453-456; b) Scott, F. L.; Barry, J. A. Free radical reactions between substituted hydrazines and sulphamyl halides. Tetrahedron Lett. 1968; 9, 513-517; c) Bougeard, P.; Johnson, M. D. Homolytic displacement at carbon: VII. Regiospecific synthesis of $S$-allyl$N, N$-dimethylsulphonamides from allylcobaloximes and the addition of $N, N$-dimethylsulphonyl chloride to terminal olefins. J. Organometal. Chem. 1981, 206, 221-227; d) Montermini, F.; Lacôte, E.; Malacria, M. Reactivity of $\beta$-Lactamido $N$-Sulfonyl Radicals. Org. Lett. 2004, 6, 921-923; e) Luo, Q.; Mao, R.; Zhu, Y.; Wang, Y. Photoredox-Catalyzed Generation of Sulfamyl Radicals: Sulfonamidation of Enol Silyl Ether with Chlorosulfonamide. J. Org. Chem. 2019, 84, 13897-13907.

(16) For further details, see Supporting Information.

(17) Chatgilialoglu, C.; Griller, D.; Rossini, S. Amino- and Alkoxysulfonyl Radicals. J. Org. Chem. 1989, 54, 2734-2737.

(18) For seminal work on halide-abstraction by silyl radicals, see: a) Lalevée, J.; Allonas, X.; Fouassier, J. P. Tris(trimethylsilyl)silane (TTMSS)-Derived Radical Reactivity toward Alkenes: A Combined Quantum Mechanical and Laser Flash Photolysis Study. J. Org. Chem. 2007, 72, 6434-6439; b) Devery, J. J. III; Nguyen, J. D.; Dai, C.; Stephenson, C. R. J. Light-Mediated Reductive Debromination of Unactivated Alkyl and Aryl Bromides. ACS Catal. 2016, 6, 5962-5967; c) Zhang, P.; Le, C. C.; MacMillan, D. W. C. Silyl Radical Activation of Alkyl Halides in Metallaphotoredox Catalysis: A Unique Pathway for Cross-Electrophile Coupling. $J$. Am. Chem. Soc. 2016, 138, 8084-8087; d) Zhu, J.; Cui, W.-C.; Wang, S.; Yao, Z.-J. Radical Hydrosilylation of Alkynes Catalyzed by Eosin Y and Thiol under Visible Light Irradiation. Org. Lett. 2018, 20, 3174-3178; e) Chatgilialoglu, C.; Ferreri, C.; Landais, Y.; Timokhin, V. I. Thirty Years of (TMS) ${ }_{3} \mathrm{SiH}$ : A Milestone in Radical-Based Synthetic Chemistry. Chem. Rev. 2018, 118, 6516-6572; f) Yu, W.-L.; Luo, Y.-C.; Yan, L.; Liu, D.; Wang, Z.-Y.; Xu, P.-F. Dehydrogenative Silylation of Alkenes for the Synthesis of Substituted Allyl silanes by Photoredox, Hydrogen-Atom Transfer, and Cobalt Catalysis. Angew. Chem. Int. Ed. 2019, 58, 10941-10945; g) Fan, X.; Xiao, P.; Jiao, Z.; Yang, T.; Dai, X.; Xu, W.; Tan, J. D.; Cui, G.; Su, H.; Fang, W.; Wu, J. Neutral-Eosin-Y-Photocatalyzed Silane Chlorination Using Dichloromethane. Angew. Chem. Int. Ed. 2019, 58, 1258012584.

(19) Qrareya, H.; Dondi, D.; Ravelli, D. Fagnoni. M. DecatungstatePhotocatalyzed Si-H/C-H Activation in Silyl Hydrides: Hydrosilylation of Electron-Poor Alkenes. Chem CatChem 2015, 7, 3350-3357.

(20) a) Chen, Y. Recent Functionalizations of Primary Sulfonamides. Synthesis 2016, 48, 2483-2522; b) Mujumdar, P.; Poulsen, S.-A. Natural Product Primary Sulfonamides and Primary Sulfamates. J. Nat. Prod. 2015, $78,1470-1477$

(21) a) Dembitsky, V. M. Bioactive cyclobutane-containing alkaloids. $J$. Nat. Med. 2008, 62, 1-33; b) Marson, C. M. New and unusual scaffolds in medicinal chemistry. Chem. Soc. Rev. 2011, 40, 5514-5533.

(22) Misale, A.; Niyomchon, S.; Maulide, N. Cyclobutenes: At a Crossroad between Diastereoselective Syntheses of Dienes and Unique Palladium-Catalyzed Asymmetric Allylic Substitutions. Acc. Chem. Res. 2016, $49,2444-2458$

(23) For examples of desulfonylation of sulfamoyl radicals, see: a) Monos, T. M.; McAtee, R. C.; Stephenson, C. R. J. Arylsulfonylacetamides as bifunctional reagents for alkene aminoarylation. Science 2018, 361, 1369-1373; b) Motherwell, W. B.; Pennell, A. M. K. J. Chem. Soc. Chem. Commun 1991, 877-879.

(24) a) Xie, J.; Xu, P.; Li, H.; Xue, Q.; Jin, H.; Cheng, Y.; Zhu, C. A room temperature decarboxylation/C-H functionalization cascade by 
visible-light photoredox catalysis. Chem. Commun. 2013, 49, 5672-5674; b) Tang, X.-J.; Thomoson, C. S.; Dolbier, Jr. W. R. Photoredox-Catalyzed Tandem Radical Cyclization of $N$-Arylacrylamides: General Methods To Construct Fluorinated 3,3-Disubstituted 2-Oxindoles Using Fluoroalkylsulfonyl Chlorides. Org. Lett. 2014, 16, 4594-4597; c) Tang, Q.; Liu, X.; Liu, S.; Xie, H.; Liu, W.; Zeng, J.; Cheng, P. N-(Acyloxy)phthalimides as tertiary alkyl radical precursors in the visible light photocatalyzed tandem radical cyclization of $N$-arylacrylamides to 3,3-dialkyl substituted oxindoles. RSC Adv. 2015, 5, 89009-89014; d) Huang, L.; Ye, L.; Li, X.-H.; Li, Z.-L.; Lin, J.-S.; Liu, X.-Y. Stereoselective Radical Cyclization Cascades Triggered by Addition of Diverse Radicals to Alkynes To Construct 6(5)6-5 Fused Rings. Org. Lett. 2016, 18, 5284-5287; e) Masu, H.; Okamoto, T.; Kato, T.; Katagiri, K.; Tominaga, M.; Goda, H.; Takayanagi, H.; Azumaya, I. Construction of macrocyclic structure using conformational properties of secondary and tertiary aromatic amides. Tetrahedron Lett.
2006, 47, 803-807; f) Zou, G.; Wang, X. Visible-light induced di- and trifluoromethylation of $\mathrm{N}$-benzamides with fluorinated sulfones for the synthesis of $\mathrm{CF}_{2} \mathrm{H} / \mathrm{CF}_{3}$-containing isoquinolinediones. Org. Biomol. Chem 2017, 15, 8748-8754; g) Yang, Z.; Tang, A. Synthesis of PerfluoroalkylSubstituted Oxindoles through Organophotoredox-Catalyzed Perfluoroalkylation of $\mathrm{N}$-arylacrylamides with Perfluoroalkyl Iodides. Synlett 2019, 30 , 1061-1066.

(25) a) Singh, G. S.; Desta, Z. Y. Isatins As Privileged Molecules in Design and Synthesis of Spiro-Fused Cyclic Frameworks. Chem. Rev. 2012 112, 6104-6155; b) Carreira, E. M.; Fessard, T. C. Four-Membered RingContaining Spirocycles: Synthetic Strategies and Opportunities. Chem. Rev. 2014, 114, 8257-8322; c) Santos, M. M. M. Recent advances in the synthesis of biologically active spirooxindoles. Tetrahedron 2014, 70, 97359757. 